\title{
The role of Cajal cells in chronic prostatitis
}

\author{
Ozgur Haki Yuksel ${ }^{1}$, Ahmet Urkmez ${ }^{2}$, Ayhan Verit ${ }^{1}$ \\ ${ }^{1}$ Department of Urology, Fatih Sultan Mehmet Research \& Training Hospital, Istanbul, Turkey; \\ 2 Haydarpasa Numune Research and Training Hospital, Dept. of Urology, Istanbul, Turkey.
}

\begin{abstract}
Summary Types of prostatitis can be defined as groups of syndromes in adult men associated with infectious and noninfectious causes characterized frequently by lower abdominal and perineal signs and diverse clinical symptoms and complications. Etiopathogenesis of chronic prostatitis is not well defined. Moreover, its treatment outcomes are not satisfactory. Presence of c-kit positive interstitial cells in human prostate is already known. It has been demonstrated that these cells can be pacemaker cells which trigger spontaneous slow-wave electrical activity in the prostate and can be responsible for the transport of glandular secretion from acinar cells into major and minor prostatic ducts and finally into urethra. In the light of all these data, when presence of a possible inflammatory pathology is thought to involve prostate that secretes and has a reservoir which drains its secretion (for prostate, prostatic urethra), two points are worth mentioning. Impairment of secretion mechanism and collection of secretion within the organ with reflux of the microbial material from its reservoir back into prostate gland. Both of these potential conditions can be explained by ductal neuromuscular mechanism, which induces secretion. We think that in this neuromuscular mechanism interstitial Cajal cells have an important role in chronic prostatitis. Our hypothesis is that curability of prostatitis is correlated with the number of Cajal cells not subjected to apoptosis.
\end{abstract}

KEY WORDS: Prostatitis; Cajal cells; Mast cells.

Submitted 17 October 2015; Accepted 8 January 2016

\section{INTRODUCTION}

Chronic prostatitis (CP) is classified as chronic bacterial prostatitis (Category 2), inflammatory chronic pelvic pain syndrome (Category 3a), non-inflammatory chronic pelvic pain syndrome (Category 3b) and asymptomatic inflammatory prostatitis (Category 4). Prostatitis affects $10-14 \%$ of men of all ages and ethnicities $(1,2)$. More than $50 \%$ of the men experiences episodes of prostatitis at one time of their lives (3). Prostatitis is the most frequently established diagnosis in men younger than 50 years of age and every year nearly 2 million people consult for examination (4). In most of the patients despite negative antibiogram results, more than one cycle of antibiotic therapy is applied $(5,6)$. In patients with unstable angina pectoris, newly developed myocardial infarction or active Crohn disease, CP becomes a disappointing experience for patients and frustrating for the physicians (7). Patients with CP typically have longlasting genitourinary/pelvic pain and obstructive and/or irritative voiding symptoms. Sexual dysfunction and psychological symptoms are frequently added to these symptoms. Interstitial cells of Cajal (ICCs) were firstly demonstrated in the urinary system in 1999 (8). In two separate studies performed by Exintaris and Shafik, the authors suggested presence of spontaneous contractile activity in the stromal layers of prostates of the guinea pig and dogs $(9,10)$. Similarly, presence of c-kit positive cells has been demonstrated in human prostate (11).

Mast cells belong to a multifunctional immune system, which secretes proinflammatory cytokines such as histamine, serotonin, leukotriene and protease with increased immunoglobulin E receptor affinity (12). Experimental studies have shown their roles in the development of autoimmune and CP $(13,14)$. Mazzoli et al. evaluated the role of interleukin 8 (IL-8) and Chlamydia trachomatis infections in patients with CP. Anti-Chlamydia trachomatis immunoglobulin A (IgA) and IL-8 were detected in $69.2 \%$ and $75.6 \%$ of patients. Moreover, the patients with higher levels of IL-8 and higher positivity for IgA reported the worst symptoms. Their results emphasize the role of immune system activation in the pathophysiology of CP (15). Besides, studies related to diseases with contractility disorder as achalasia have demonstrated that mast cells are closely associated with ICCs. These cells degranulate and lead the related cells to death via cytokine release and autophagy. We think that in $\mathrm{CP}$, prostatic ductal contractility disorder occurs. Therefore medical treatment of prostatitis should be evaluated accordingly and appropriate treatment with mast cell degranulation inhibitors at an optimal time before total Cajal cell apoptosis occurs will achieve permanent treatment response.

\section{Evaluation OF THE hYPOTHESIS}

High-pressure voiding dysfunction, intraprostatic ductal reflux (chemical mechanism), microbial etiology, autoimmune and neuromuscular mechanisms are thought to play a role in the etiopathogenesis of CP. CP is defined and classified with culture and microscopic examination of prostatic secretions and segmental urine samples as described by Meares and Stamey in addition to its peculiar symptoms (16). Bartoletti et al. evaluated the role of 
biofilm- producing bacteria in patients with negative microbiological results and persistent $\mathrm{CP}$ symptoms. They found that biofilm- producing bacteria were commonly isolated and had a significant negative effect on clinical response to antibiotic treatment (17). The presence of bacterial biofilm could be the "primum movens" of the flogosis process in the prostatic tissue. The role of Cajal cells in continuing this process could be interesting to evaluate. CP can also occur without any evidence of bacterial or demonstrable prostatic infection (18). Many investigators have proposed neuromuscular etiology in inflammatory and non-inflammatory prostatitis $(19,20)$. Chronic pain associated with these syndromes is definitively of neuropathic type. According to one hypothesis, non-inflammatory prostatitis can emerge as a form of reflex sympathetic dystrophy. If perineum/pelvic wall is thought as a distal extremity, then this opinion deserves to be evaluated. Symptoms of all patients with noninflammatory prostatitis closely resemble to those with cases of reflex sympathetic dystrophy. This perspective should be investigated and validated in further more sophisticated studies (18).

In recent studies, presence of spontaneous contractile activities in the prostatic stroma of guinea pig and dogs has been suggested $(9,10)$. It has been demonstrated that this spontaneous contractile activity enhances with entry of calcium into L-type calcium ( $\mathrm{Ca}++)$ channels and that these short-acting spontaneous depolarizations at 5-15 $\mathrm{mV}$ amplitude trigger one or more than one nifedipine sensitive $\mathrm{Ca}++$ voltage increments. These slow-waves have myogenic origins and they are not effected by blockers of conduction of action potential, sympathetic, parasympathetic, sensorial and synaptic nerve impulse transmission or prostaglandin synthetase inhibitors. In the prostates of guinea pigs, conduction networks of c-kit positive cells have been located between glandular and stromal muscle layers of prostate acini and in the stromal smooth muscle layer (9). Similarly, presence of c-kit positive cells has been shown in the human prostate (11). Discovery of slow-waves and ICCs in the prostate gland of guinea pigs has suggested that activities of these slowwaves may be responsible for spontaneous tonus of the human prostate. According to these experimental animal models, in patients with diseases which progress with decreased intestinal motility including diabetes, chronic or inflammatory bowel diseases, and in those with defective interstitial cell network, there is higher probability of development of benign prostatic hyperplasia (BPH) due to ICC-like cell dysfunction (21). In another study, it is stated that intraprostatic slow wave activity may be important role in the etiology of $\mathrm{BPH}$ and symptoms related to $\mathrm{BPH}$ (22).

Up to now, embryological origin of ICCs has not been understood and in consideration of their resemblance to neural cells, they have been probably thought to originate from neural crest. However, many studies have demonstrated that they do not stem from neural crest, but develop independently from enteric neurons. In recent literature, Cajal cells are thought to be originated from mesenchymal precursor cells that have gained momentum (23). ICCs have been found to be promising in the elucidation of motor physiology and pathophysi- ology of luminal organs. In recent years, thanks to advances in the developments in histopathological and immunohistochemical diagnostic methods, studies investigating location, function and the role of ICC in the pathophysiology of urinary system diseases are still continuing. In a study where total urinary system postmortem tissue samples harvested from pigs were investigated, three groups of cells with c-kit receptor (CD 117) positivity were detected. Spindle-shaped interstitial cells included in the first cell group had been demonstrated to have oval nuclei, bipolar cytomorphological structure and two thin wavy extensions; the second group consisted of CD 177 positive mast cells and the third group comprised of vertically aligned cells located on the epithelial basal layers (24). In a study where intramural ureters of the patients with vesicoureteral reflux of various degree were compared as for the presence of c-kit positive cells, marked decrease in interstitial cells interposed between muscle fascicles, which are replaced by connective tissue in relation with the degree of vesicoureteral reflux was detected. In the ureteral unit with reflux, decrease in baseline and maximum intraureteral pressures and associated decrease in c-kit positive interstitial cells were detected (25). In a study performed on human urethra, the presence of c-kit positive cells was demonstrated between smooth muscle fibers and in the border layer between urothelium and lamina propria (26). In another study where distribution of ICCs was compared in patients with congenital obstructive megaureter, a prominent decrease both in the smooth muscle ratio and the number of c-kit positive cells were detected (27). As it was noted previously, literature studies on ICCs have been performed involving a wide spectrum of anatomical sites extending from renal calyces to urethra or even spontaneous contractile activity of vas deferens and spermatogonia. Absence of ICCs has been associated with both relative obstruction and also mechanism of reflux. Still in various studies the role of mast cells in prostatitis and interstitial cystitis has been indicated (28, 29) and supported by experimental studies (14).

Theoretically, mast cells increase regeneration capacity of Cajal cells and subsequent increase in the density of Cajal cells is perceived as a tumoral activity by immune system and the process terminates dramatically with apoptosis of all Cajal cells. Studies in achalasia have demonstrated that ICCs modulate electrical activity generated by nitrergic and VIPergic neurons, which also control muscular contractions before transmitting this activity to the muscle cells by delaying its transport in micron- sized gaps between ICCs. This modulation is realized in various frequencies and it is valid for all digestive systems. This is called 'gap function', which operates just like a condenser in physics and delays the transport of 'directives' set forth so as to control muscular contractions. Therefore, various medical treatments that can regulate activation of mast cells will obviously provide infinite benefits in the treatment of diseases presumably associated with ICC-related contractility disorders.

In literature reviews, ICCs have been analyzed in cases of many urological pathologies including ureteropelvic junction obstruction, primary obstructive megaureter, congenital vesicoureteral junction obstruction and overactive 
detrusor and were evaluated as a urological pacemaker. We have observed that clinical findings of these abovementioned diagnoses are generally associated with infections, which are pathophysiologically explained with a mechanism of stasis (29-32). Our hypothesis points a similar mechanism that should present in the prostate tissue, which produces nearly $30 \%$ of seminal fluid (33).

\section{Conclusion}

Our hypothesis confirmed the infective etiology of $\mathrm{CP}$ as the result of the intraprostatic stasis due to the ICC deficiency. Pathophysiologic mechanism of $\mathrm{CP}$ and the presence of intraprostatic ICC may explain the etiology of this pathology and identify the therapeutic target of this seemingly challenging disease encountered in the urology practice.

\section{References}

1. Mehik A, Hellstrom P, Lukkarinen O, et al. Epidemiology of prostatitis in Finnish men: A population- based cross sectional study. BJU. 2000; 86:443-448.

2. Nickel JC, Downey J,Hunter D, Clark J. Prevance of prostatitis like symptoms in a population based study using the National Institutes of Health chronic prostatitis symptom index. J Urol. 2001; 165:842-845.

3. Stamey T. Urinary tract infections in males. In: Stamey T, Editor. Pathogenesis and treatment of urinary tract infections. Baltimore: Williams and Wilkins. 1980; pp. 342-429.

4. Collins MM, Stafford RS, O'leary MP, Barry MJ. How common is prostatitis? A national survey of physician visits. J Urol. 1998; 159:1224-1228.

5. Nickel JC. Prostatitis: Myths and realities. Urology. 1998; 51:362366.

6. McNaughton Collins M, Fowler FJ Jr, Elliott DB, et al. Diagnosing and treating chronic prostatitis: Do urologists use the four glass test? Urology. 2000; 55:403-407.

7. Wenninger K, Heiman JR, Rothman I, et al. Sickness impact of chronic nonbacterial prostatitis and its correlates. J Urol. 1996; 155:965-968.

8. Klemm MF, Exintaris B, Lang RJ. Identification of the cells underlying pacemaker activity in the guinea-pig upper urinary tract. J Physiol. 1999; 519:867-884.

9. Exintaris B, Klemm FM, Lang JR. Spontaneous slow wave and contractile activity of the guinea pig prostate. J Urol. 2002; 168:315-322.

10. Shafik A. Electroprostatogram: an experimental study. Mol Androl. 1996; 8:73-79.

11. Van der A, Roskans T, Blyweert W. Interstitial cells in the human prostate: a new therapeutic target? Prostate. 2003; 56:250-255.

12. Ren S, Sakai K, Schwartz LB. Regulation of human mast cell beta-tryptase: conversion of inactive monomer to active tetramer at acid ph. J Immunol. 1998; 160:4561-4569.

13. Donadio AC, Depiante-Depaoli M. Inflammatory cells and MHC class II antigens expression in prostate during time-course experimental autoimmune prostatitis development. Clin Immunol Immunopathol. 1997; 85:158.

14. Keith IM, Jin J, Neal D Jr, et al. Cell relationship in a Wistar rat model of spontaneous prostatitis. J Urol. 2001; 166:323-328.

15. Mazzoli S, Cai T, Rupealta V, et al. Interleukin 8 and anti- chlamydia trachomatis mucosal IgA as urogenital immunologic markers in patients with C. trachomatis prostatic infection. Eur Urol. 2007; 51:1385-93.

16. Meares EM, Stamey TA. Bacteriologic localization patterns in bacterial prostatitis and uretritis. Invest Urol 1968; 5:492-518.

17. Bartoletti R, Cai T, Nesi G, et al. The impact of biofilm-producing bacteria on chronic bacterial prostatitis treatment: results from a longitudinal cohort study. World J Urol. 2014; 32:737-42.

18. Nickel JC. Prostatitis: evolving management strategies. Urol Clin North Am. 1999; 26:737-751.

19. Andersen JT. Treatment of prostatodynia. In Nickel JC (Ed): Textbook of Prostatitis. London ISIS, 1999.

20. Egan KJ, Krieger JL. Chronic abacterial prostatitis--a urological chronic pain syndome? Pain. 1997; 69:213-218.

21. Exintaris B, Nguyen DT, Dey A, Lang RJ. Spontaneous electrical activity in the prostate gland. Auton Neurosci. 2006; 30;126-127.

22. Exintaris B, Nguyen DT, Lam M, Lang RJ. Inositol trisphosphate-dependent Ca stores and mitochondria modulate slow wave activity arising from the smooth muscle cells of the guinea pig prostate gland. Br J Pharmacol. 2009; 156:1098-106.

23. Metzger R, Neugebauer A, Rolle U. C-Kit receptor (CD117) in the porcine urinary tract. Pediatr Surg Int. 2008; 24:67-76.

24. Arena S, Fazzari C, Arena F. Altered "active" antireflux mechanism in primary vesico-ureteric reflux: a morphological and manometric study. BJU Int. 2007; 100:407-412.

25. Hyo JK, Hye YL, Mei H. Decreased interstitial cells of Cajal-like cells, possible cause of congenital refluxing megaureters: histopathologic differens in refluxing and obstructive megaureters. Ped Urol. 2009; 74:318-323

26. Van $\operatorname{der} A$, Roskans T, Blyweert W. Identification of kit positive cells in the human urinary tract. J Urol. 2004; 171:2492-2496.

27. Pontari MA, Ruggieri MR. Mechanisms in prostatitis/chronic pelvic pain syndrome. J Urol. 2004; 172:839.

28. Elbadawi A. Interstitial cystitis: a critique of current concepts with a new proposal for pathologic diagnosis and pathogenesis. Urology. 1997; 49:14-40

29. Di Benedetto A, Arena S, Nicotina PA, et al. Pacemakers in the upper urinary tract. Neurourol Urodyn. 2013; 32:349-353.

30. Apoznanski W, Koleda P, Wozniak Z, et al. The distribution of interstitial cells of Cajal in congenital ureteropelvic junction obstruction. Int Urol Nephrol. 2013; 45:607-612.

31. Juszczak K, Maciukiewicz P, Drewa T, Thor PJ. Cajal-like interstitial cells as a novel target in detrusor over activity treatment: true or myth? Cent European J Urol. 2014; 66:413-417.

32. Eken A, Erdogan S, Kuyucu Y. Immunohistochemical and electron microscopic examination of Cajal cells in ureteropelvic junction obstruction. Can Urol Assoc J. 2012; 10:1-6.

33. Turunc T, Bayazit Y, Doran F, Bal N, Doran S. Effects of vas deferens obstruction on Cajal-like cells in rats. Urol Int. 2009; 83:86-91.

\section{Correspondence}

Ozgur Haki Yuksel, MD (Corresponding Author)

ozgurhaki@gmail.com

Ayhan Verit, MD, Prof.

Department of Urology, Fatih Sultan Mehmet Research \& Training Hospital Içerenköy/Atasehir Tr- 34752 Istanbul, Turkey

Ahmet Urkmez, MD

Haydarpasa Numune Research and Training Hospital, Dept. of Urology Istanbul, Turkey 